\title{
German Heart Surgery Report 2020: The Annual Updated Registry of the German Society for Thoracic and Cardiovascular Surgery
}

\author{
Andreas Beckmann ${ }^{1}$ Renate Meyer ${ }^{2}$ Jana Lewandowski ${ }^{1}$ Andreas Markewitz ${ }^{1}$ Jan Gummert ${ }^{3}$ \\ ${ }^{1}$ German Society for Thoracic and Cardiovascular Surgery, \\ Langenbeck-Virchow-Haus, Berlin, Germany \\ 2 BQS Institute for Quality and Patient Safety, Hamburg, Germany \\ ${ }^{3}$ Clinic for Thoracic and Cardiovascular Surgery, Heart and Diabetes \\ Center NRW, Bad Oeynhausen, Germany

\begin{abstract}
Address for correspondence Andreas Beckmann, MD, Deutsche Gesellschaft für, Thorax-, Herz- und Gefäßchirurgie [DGTHG], Langenbeck-Virchow-Haus, Luisenstr. 58-59, 10117 Berlin, Germany (e-mail: gf@dgthg.de).
\end{abstract}

Thorac Cardiovasc Surg 2021;69:294-307.

\begin{abstract}
Keywords

- heart valve surgery

- congenital heart disease

- coronary artery bypass grafting

- aortic surgery

- transplantations

- heart-lung

- COVID-19

Based on a longtime voluntary registry, founded by the German Society for Thoracic and Cardiovascular Surgery (GSTCVS) in 1980, well-defined data of all cardiac, thoracic and vascular surgery procedures performed in 78 German heart surgery departments during the year 2020 are analyzed. Under the more than extraordinary conditions of the ongoing worldwide coronavirus disease 2019 pandemic, a total of 161,817 procedures were submitted to the registry. A total of 92,809 of these operations are summarized as heart surgery procedures in a classical sense. The unadjusted in-hospital survival rate for the 29,444 isolated coronary artery bypass grafting procedures (relationship on-/off-pump $3.6: 1)$ was $97.2 \%$. For the 35,469 isolated heart valve procedures, $(17,471$ transcatheter interventions included), the survival rate was $96.7 \%$. Concerning short- and long-term circulatory support, a total of 2,852 extracorporeal life support/extracorporeal membrane oxygenation implantations, respectively, 843 assist device implantations (left/right/biventricular assist device, total artificial device), were registered. In 2020, the number of isolated heart transplantations increased to 340 , a rise of $2.1 \%$ compared with the previous year. The isolated lung transplantations amounted to 291 , a decrease of $6.4 \%$.

This annually updated registry of the GSTCVS represents voluntary public reporting by accumulating actual information for nearly all heart surgical procedures in Germany, constitutes advancements in heart medicine, and represents a basis for quality management for all participating institutions. In addition, the registry demonstrates that the provision of cardiac surgery in Germany is up to date, appropriate, and nationwide patient treatment is guaranteed all the time.
\end{abstract}

\section{Introduction}

Legitimate demands for a sophisticated quality management in medicine-by authorities, scientific organizations, health care companies, and patients all over the world-have stimulated a quality awareness. This resulted in the development of versatile quality assurance activities such as benchmark projects, public reporting, registries, and others to answer

received

April 26, 2021

accepted

April 26, 2021

those needs. More than 30 years ago the board of directors of the German Society for Thoracic and Cardiovascular Surgery (GSTCVS, www.dgthg.de) decided to set up a periodic data collection of all cardiac surgical procedures in terms of a voluntary, unaudited registry. ${ }^{1,2}$ Since 1989 , the data are updated annually, summarized in the sense of a scientific registry, and published in the scientific society journal each year. ${ }^{3-7}$ The prevalent aims are to detect developments and

(c) 2021. Thieme. All rights reserved. Georg Thieme Verlag KG,

Rüdigerstraße 14,

70469 Stuttgart, Germany
DOI https://doi.org/ 10.1055/s-0041-1730374. ISSN 0171-6425. 
upcoming trends in cardiac surgery in Germany, to compile various results for nearly all cardiac surgical procedures, to provide each participant with a benchmark of the institutional results to the nationwide achievements, and to facilitate an evaluation on an international level for the GSTCVS.

For monitoring actual conditions as well as developments in cardiac medicine, the registry covers all relevant techniques and also innovative technologies including minimally invasive cardiac surgery as well as all kinds of heart valve procedures, including transcatheter heart valve interventions (e.g., TAVI). Thereby, important findings for current patient safety and the future of patient care are collected for evaluation under different aspects.

Data presented in this report comprehend the survey of the year 2020 whereby the more than special circumstances, caused by the coronavirus disease 2019 (COVID-19) pandemic, must necessarily be taken into account when interpreting the results.

\section{Materials and Methods}

Since 2004 a standardized questionnaire gathers specific information for well-defined procedures, exactly described by an annually updated German adaption of the International Classification of Procedures in Medicine called "operation code” (OPS: Operationen- und Prozedurenschlüssel).

All participating institutions were requested to complete the structured questionnaire by January 25, 2021, entering all performed procedures and associated in-hospital mortality. The recommended path for data export is an electronic transmission of an encrypted file to the society office in Berlin. After transaction, the data were decrypted, evaluated for completeness and compiled for further analysis, thus ensuring anonymity for each participating institution. This compilation algorithm enables a high compliance for submission of complete datasets.

Inclusion criteria for the registry data 2020 were all cardiac surgical procedures performed on patients between January 1 , 2020 and December 31,2020, unrelated to the date of patients' admission or discharge as compared with other registries. Like in the earlier years, the number of procedures was counted rather than individual patients. For example, if a patient initially required isolated coronary artery bypass grafting $(\mathrm{CABG})$, later followed by a mitral valve reconstruction due to an undesirable event, one count in the category "coronary surgery" and a second one in the category "mitral valve reconstruction" are enumerated. Thus, the registry contains more procedures than the real number of patients operated on.

Death of patients was defined as in-hospital mortality. Per definition, the observed mortality is always attributed to the first cardiac procedure, for example, the death of a patient requiring a replacement of the ascending aorta due to a complication after CABG would only be attributed to the coronary procedure.

The main reason for this structural setup of the registryestablished over three decades-is to keep in accordance with the German data privacy act with its specific regulations for patients. Furthermore, it seemed to be relevant to get detailed information about all performed procedures and not only the number of treated patients. Last but not least the process of data acquisition had to be standardized and feasible for all participating departments in Germany, thus enabling the submission of a complete dataset, regardless of the hard- and software used locally.

In 2020, a total of 78 institutions performed heart surgery. As in the years before, all departments answered the questionnaire and delivered a complete dataset for the year 2020, including in-hospital mortality rates. In addition, comparisons between the registry data and the external quality assurance in accordance with $\S \S 135 \mathrm{a} / 136 / 137$ SGB V, obligatory for licensed German hospitals ( $§ 108$ SGB V), are feasible.

For descriptive statistical analyses categorized tables and a summary registry data file consolidate the transmitted information of all departments, providing the basis for this and further publications. Longitudinal data from earlier registry specifications are also included in the presentation. The period considered is restricted to the past 10 years.

Categorical data are displayed as absolute and/or relative frequencies. Due to lack of complete data for patients' risk adjustment, all mortality rates are unadjusted. Quantitative data are presented as absolute frequencies and arithmetic mean values. Where appropriate, the value range is presented additionally. Patient age, though originally a quantitative variable, is only available in age groups and therefore treated as a categorical variable. German population-based measures are calculated as frequencies per 100,000 inhabitants and are based on the latest published data of the Federal Office for Statistics (Destatis) dated December 31, 2019.

The questionnaires were compiled using Microsoft Visual Basic for Applications. Analyses were performed with IBM SPSS Statistics v22 and Microsoft Excel 2010, and charts and tables were created with Microsoft Excel 2010.

\section{Registry Data 2020}

-Table 1 shows the distribution of cardiac surgical procedures between the 16 German states, based on the population count of the Federal Office for Statistics as of December 31, 2019. The range of heart operations per 100,000 inhabitants again shows a minimum of 94.4 (Bavaria, population: $13,124,737$ ) and a maximum of 167.0 (Sachsen-Anhalt, population: 2,194,782), while the nationwide mean-value by the end of 2020 was 110.9 (-Table 1). In addition, - Table 1 shows a state-by-state representation of confirmed COVID- 19 cases/100,000 population with a median of 1,981 (range: 2,504), a minimum of 746 in Mecklenburg-Vorpommern and maximum of 3,250 in Sachsen. Analyzing quantified categories of heart operations by department dimension, categorizes more than $69 \%$ of institutions into two clusters with at least 541 up to 1,497 procedures, $22 \%$ into those with a minimum of 1,502 up to a maximum of 3,981 performed procedures (-Table 2 ). Summarizing the departments by various heart surgical procedures, it can be asserted that heart operations in patients for congenital heart disease (CHD) $(<1$ year, with extracorporeal circulation [ECC]) are conducted in 21, isolated heart transplantations in 19, and combined heart-lung transplantations in 1 institution (-Table $\mathbf{3}$ ). 
The number of procedures using ECC in Germany from 2011 to 2020 is illustrated in - Table 4. The comparison from 2019 to 2020 shows a decline by 8,039 procedures, presumably reflecting an enormous effect of the COVID-19 pandemic and only to a small extent the achievement of established innovations, especially minimally invasive heart surgical options.

Overall, 161,817 procedures were reported to the registry for the year 2020, a difference of $7.9 \%$ compared with 2019 (175,705 procedures). In 2020 , a total of 92,809 heart surgical procedures in the narrower sense displays a COVID-19-related decrease of 7.6\% $(n=7,637)$ compared with $2019(100,446$ procedures) (-Table 5). Concerning gender distribution, the registry shows an overall male/female ratio of almost 2:1 with the greatest difference (4:1) in the patient group with coronary procedures (-Table 6 ). About $11.3 \%(n=10,445)$ of the operations were conducted as emergency procedures, and $7.9 \%$ $(n=7,330)$ were reoperations ( - Table 7 ). A total of 14,773 $(41.7 \%)$ isolated heart valve procedures were performed as single, 2,836 as double ( $8.0 \%)$, and $289(0.8 \%)$ as triple valve procedures ( - Table V1). A total of 3,006 (36.7\%) aortic valve and 3,342 (55.2\%) mitral valve operations were performed via a minimally invasive access (- Table V2). In 7,194 (87.9\%) isolated aortic valve operations using ECC, xenograft prostheses were implanted, while in 3,878 (64.1\%) isolated mitral valve operations, a reconstruction with preservation of the native mitral valve could be achieved ( - Table V3, - Figs. 5 and 7). In a total of 2,594 combined mitral valve repair procedures, 1,115 (43.0\%) simultaneous CABG procedures, 825 tricuspid valve repairs (31.8\%), 447 (17.2\%) aortic valve procedures, and 207 (8.0\%) concomitant CABG and aortic valve replacement (AVR) were performed (-Table V4). The subgroup of 3,125 multiple heart valve procedures amounted to $2,613(83.6 \%)$ operations, as a combination of mitral + tricuspid $(n=1,406)$ or mitral + aortic $(n=1,207)$ valve procedures (-Table V5). Regarding 15,621 transcatheter aortic valve implantations (TAVI), 14,275 (91.4\%) procedures were performed by transvascular and 1,346 (8.6\%) by transapical access. In TAVI procedures without ECC, the unadjusted mortality for those by transvascular access was $1.9 \%(n=277)$ and $5.2 \%$ $(n=70)$, respectively, for the transapical approach. On the other hand, TAVI under use of ECC shows a remarkably high unadjusted mortality rate of $27.1(n=70)$ resp. $30.0 \%(n=10)$ (-Table V6), probably related to complications during the initial procedure.

Concerning 37,979 CABG procedures, $77.5 \%$ were performed as isolated operations $(n=29,444), 11.7 \%(n=4,436)$ combined with AVR and $5.1 \%(n=1,930)$ with simultaneous mitral valve procedures ( $\boldsymbol{- T a b l e} \mathbf{C} \mathbf{1}$ ). $\boldsymbol{-}$ Table $\mathbf{C} \mathbf{2}$ provides an overview of the isolated CABG operations focused on the number of bypass grafts and indicates the corresponding unadjusted mortality rates for on/off pump surgery.

- Tables Con1 and Con2 and Mis1 to Mis5 demonstrate further compiled registry data under different aspects and for various categories.

Compared with the data of previous years some significant changes can be seen on one hand, while several developments remained almost unchanged in 2020 on the other hand. The number of CABG procedures, isolated or combined, shows a remarkable decrease of $13.9 \%$ in 2020 , while for isolated heart valve procedures, the difference is just $3.2 \%$ ( - Fig. 1). However, unadjusted mortality rates for CABG, AVR, and mitral valve procedures vary just slight over the last decade (-Fig. 2). The age distribution of patients continues to evolve toward an elderly patient population ( - Fig. 3). Presently, $32.2 \%$ of the cardiac procedures are performed in patients from 70 to 79 years of age, and $19.2 \%$ were in octo-/nonagenarians. The relative number of isolated off-pump CABG is steadily increasing, reaching 21.9\% in 2020 (2019: 20.7\%) (-Fig. 4).

With regard to prosthetic valve distribution in $89.7 \%$ $(n=7,194)$ the sAVR was performed using a xenograft, while (-Fig. 5) in $10.3 \%(n=830)$ a mechanical prosthesis was implanted. The unchanged development of transcatheter heart valve procedures in Germany leads to a total of 17,354 procedures in 2020 (-Table V6). For the last year, 15,701 (66.1\%) TAVI and 8,049 (33.9\%) surgical aortic valve replacement (sAVR) procedures were reported to the registry ( - Fig. 6). It must be emphasized that exclusively the German departments for cardiac surgery contribute these data. Therefore, the registry cannot reach completeness because procedures documented by cardiology departments are missed. On the basis of and in addition to the recommendations of international scientific guidelines, expert consensus on the management of valvular heart disease, ${ }^{8-11}$ the German Federal Joint Committee (G-BA) implemented a quality assurance directive ${ }^{12}$ for "minimally invasive heart valve interventions (TAVI, transcatheter mitral clip reconstruction)", currently under evaluation. Further surveys for selected procedures, such as the legally compulsory quality assurance ( $\$ 135$ a SGB V) or the voluntary nationwide German Aortic Valve Registry (GARY), ${ }^{13-23}$ provide various important findings and thus also contribute to an exceptional patient benefit.

In 2020, the rate of isolated mitral valve reconstructions remains almost unchanged on a remarkable level of $64.1 \%$ (2019: 64.5\%) ( - Fig. 7). Based on the fact that each isolated mitral valve procedure is included, regardless of the underlying mitral valve disease concerning morphology or urgency of operation, it can be assumed that the relative rate of mitral valve reconstruction would certainly be even higher if patients without a possibility or indication for reconstruction would have been excluded (e.g., mitral valve stenosis, calcifications, or endocarditis). In other publications, for example, Gammie et $\mathrm{al}^{24}$ patients with mitral valve stenosis, endocarditis, and emergency procedures are usually excluded. Therefore, other published rates of mitral valve repair have to be interpreted with caution if compared with this registry.

In 2020, almost half ( $48.9 \% ; n=2,721$ ) of cardiac operations for CHD were performed in neonates/infants $<1$ year, $35.1 \%$ in children between 1 and 17 years, and $16.0 \%$ in patients at least 18 years of age ( $\mathbf{F i g . 8}$ ). Concerning ventricular assist device (left/right/biventricular assist device, total artificial heart) implantations ( $n=843)$, a significant decrease of $11.5 \%$ compared with 2019 ( $n=953)$ ( - Fig. 9) could be observed, while the heart transplantations increased to 340 (2019: $n=333$ ) (-Fig. 10). Nevertheless, the mechanical circulatory support therapy, in particular LVAD, is still of outstanding importance for patients with end-stage heart failure. 


\section{Discussion}

Even under the exceptional conditions of the CoVID-19 pandemic, the registry of the GSTCVS enables a comprehensive overview of all heart surgical procedures performed in Germany in 2020. The accuracy of this registry remains high due to the implemented compilation algorithm using standardized operation coding as a relevant criterion for reimbursement purposes. This is supported by other authors who could demonstrate a high accuracy for major outcome parameters in unaudited registries. ${ }^{25}$ As observed in recent years, heart surgery in Germany is performed on a high level with superior in-hospital patient survival compared with international surveys. In addition, the registry demonstrates that the provision of cardiac surgery in Germany could be guaranteed nationwide even under COVID-19 at all times (24/7/365). These aspects are especially important in the context of various activities in health care policy and considering the background of demographic trends of the German population, leading to patients at increased age combined with related comorbidities and an accordingly complex perioperative risk profile.

Compared with 2019, the number of cardiac surgery procedures showed a relevant decrease for isolated/combined CABG and sAVR, an ongoing trend in view of the German population characteristics and in the context of application of the scientific guidelines. ${ }^{26,27}$ Despite this for the year 2020, it must be taken into account that the care of patients with heart disease was affected by the consequences of the severe acute respiratory syndrome coronavirus 2 pandemic with repeated shutdowns throughout Germany and various restrictions of elective/urgent heart surgical procedures due to limited intensive care resources in all German cardiac centers. Otherwise, the renewed increase in heart transplantations is a reason for hope that this positive development will continue.

Further improvements of the registry are recommended to enable more specified assessments and particularly riskadjusted data analyses. However, if significant fundamental changes related to the modality of data collection were to be implemented, a modified structure would have to ensure further longitudinal data analysis.

Completeness, validity, and further progress depend on continued efforts and a close collaboration of the GSTCVS and all cardiac surgical departments in our country. This will be of outstanding importance as a contribution for patient safety and to obtain evidence for the high quality of heart surgery in Germany.

Conflict of Interest

None declared.

\section{Acknowledgments}

The German Society for Thoracic and Cardiovascular Surgery would like to thank all heads of the departments for cardiac surgery in Germany and their employees for their continued cooperation and support to realize the annual update of this registry.

\section{Abbreviations}

ASD atrial septal defect

AVC Atrioventricular canal

CABG coronary artery bypass grafting

CHD congenital heart disease

CIED Cardiac Implantable Electronic Devices

DLTx double lung transplantation

DORV double outlet right ventricle

ECC extracorporeal circulation

ECLS extracorporal life support

ECMO extracorporal membrane oxygenation

HLTx heart-lung transplantation

HTx heart transplantation

ICD implantable cardioverter defibrillator

LTx lung transplantation

PDA patent ductus arteriosus

PTS patients

SAVR surgical aortic valve replacement

SLTX single lung transplantation

TAH total artificial heart

TAVI transcatheter aortic valve implantation

TGA transposition of great arteries

TMLR transmyocardial laser revascularization

Tx transplantation

VAD ventricular assist device

VSD ventricular septal defect 
Tables and Figures

Table 1 German states/Heart operations/confirmed COVID-19 cases

\begin{tabular}{|c|c|c|c|c|c|}
\hline Federal state & Population $^{a}$ & Quantity $^{\mathrm{b}}$ & $\begin{array}{l}\text { Heart procedures/ } \\
100,000 \text { inhabitants }\end{array}$ & $\begin{array}{l}\text { Total number of } \\
\text { COVID-19 } \text { cases }^{c}\end{array}$ & $\begin{array}{l}\text { COVID-19 cases/ } \\
100,000 \text { population }\end{array}$ \\
\hline Baden Württemberg & $11,100,394$ & 10,842 & 97.7 & 237,993 & 2,144 \\
\hline Bayern & $13,124,737$ & 12,384 & 94.4 & 324,937 & 2,476 \\
\hline Berlin & $3,669,491$ & 3,738 & 101.9 & 96,788 & 2,638 \\
\hline Brandenburg & $2,521,893$ & 3,291 & 130.5 & 41,241 & 1,635 \\
\hline Bremen & 681,202 & 736 & 108.0 & 13,559 & 1,990 \\
\hline Hamburg & $1,847,253$ & 2,231 & 120.8 & 36,417 & 1,971 \\
\hline Hessen & $6,288,080$ & 6,554 & 104.2 & 136,577 & 2,172 \\
\hline Mecklenburg-Vorpommern & $1,608,138$ & 2,060 & 128.1 & 11,997 & 746 \\
\hline Niedersachsen & $7,993,608$ & 9,223 & 115.4 & 106,789 & 1,336 \\
\hline Nordrhein-Westfalen & $17,947,221$ & 20,363 & 113.5 & 393,185 & 2,191 \\
\hline Rheinland-Pfalz & $4,093,903$ & 4,656 & 113.7 & 71,993 & 1,759 \\
\hline Sachsen & $4,071,971$ & 4,864 & 119.5 & 132,356 & 3,250 \\
\hline Sachsen-Anhalt & $2,194,782$ & 3,665 & 167.0 & 29,200 & 1,330 \\
\hline Schleswig-Holstein & $2,903,773$ & 3,730 & 128.5 & 24,792 & 854 \\
\hline Thüringen & $2,133,378$ & 2,814 & 131.9 & 42,034 & 1,970 \\
\hline Germany & $83,166,711$ & 92,270 & 110.9 & $1,719,737$ & 2,068 \\
\hline
\end{tabular}

${ }^{\mathrm{a}}$ Federal Office for Statistics of German Population; due date Dec 31, 2019.

${ }^{b} n=539$, foreign residences excluded.

'Robert Koch Institute: laboratory confirmed COVID-19 cases; due date Dec 31, 2020 12:00 AM.

Table 2 Departments assorted by quantified categories ( $\left.\Sigma^{\mathrm{a}}[n=92,809]\right)$

\begin{tabular}{|l|l|l|l|l|}
\hline Procedures (quantity) & $<500$ & $\mathbf{5 0 0 - 9 9 9}$ & $\mathbf{1 , 0 0 0 - 1 , 4 9 9}$ & $\mathbf{2 , 0 0 0 - 5 , 0 0 0}$ \\
\hline Departments & 7 & 32 & 22 & 7 \\
\hline Average & 343 & 784 & 1,215 & 10 \\
\hline Range & $186-451$ & $541-988$ & $1,009-1,497$ & 1,700 \\
\hline
\end{tabular}

${ }^{\mathrm{a} C I E D}$ and extracardiac surgery without ECC are excluded.

Table 3 Departments summarized by heart surgery procedures 2020

\begin{tabular}{|l|l|l|}
\hline Category & $n$ \\
\hline Coronary artery bypass grafting & 77 \\
\hline Heart valve surgery & 77 \\
\hline Pacemaker/ICD procedures & $75 / 72$ & \\
\hline Surgery for CHD (pat. $<1$ year with ECC) & $21^{\text {a }}$ \\
\hline Heart transplantation & $19^{\text {b }}$ & \\
\hline Heart-lung transplantation & 1 \\
\hline
\end{tabular}

${ }^{a} n=2,061$ : thereof: $24-43$ op. in 6, 59-89 op. in 5, 108-211 op. in 10 units.

${ }^{b} n=340$ : thereof: 2-4 transpl. in 5, 7-9 transpl. in 4, 11-20 transpl. in 4, 28-73 transpl. in 6 units.

Table 4 Cardiac procedures using extracorporeal circulation (2011-2020)

\begin{tabular}{|c|c|c|c|c|c|c|c|c|c|c|}
\hline & 2011 & 2012 & 2013 & 2014 & 2015 & 2016 & 2017 & 2018 & 2019 & 2020 \\
\hline Departments & 78 & 79 & 79 & 78 & 78 & 78 & 78 & 78 & 78 & 78 \\
\hline Operations & 84,402 & 84,388 & 84,040 & 83,787 & 81,527 & 79,082 & 76,696 & 72,331 & 71,759 & 63,720 \\
\hline Average & 1,082 & 1,068 & 1,064 & 1,074 & 1,045 & 1,014 & 983 & 927 & 920 & 817 \\
\hline
\end{tabular}


German Heart Surgery Report 2020 Beckmann et al. 299

Table 5 Frequency of cardiac procedures 2020

\begin{tabular}{|l|l|l|l|l|}
\hline Category & $\begin{array}{l}\text { With } \\
\text { ECC }\end{array}$ & $\begin{array}{l}\text { Without } \\
\text { ECC }\end{array}$ & Total & $\begin{array}{l}\text { Diff. 2019 } \\
(\%)\end{array}$ \\
\hline CABG isolated & $23,004^{\mathrm{a}}$ & $6,440^{\mathrm{a}}$ & 29,444 & $-14.0 \%$ \\
\hline CABG combined & 8,359 & 181 & 8,540 & $-13.5 \%$ \\
\hline Heart valve procedures & $18,137^{\mathrm{a}}$ & $17,332^{\mathrm{a}}$ & 35,469 & $-3.2 \%$ \\
\hline Surgery of thoracic aorta & $7,177^{\mathrm{a}}$ & $655^{\mathrm{a}}$ & 7,832 & $-5.0 \%$ \\
\hline Surgery for CHD & $4,714^{\mathrm{a}}$ & $855^{\mathrm{a}}$ & 5,569 & $-3.3 \%$ \\
\hline Cardiac surgery, other & $1,278^{\mathrm{a}}$ & $1,251^{\mathrm{a}}$ & 2,529 & $-5.9 \%$ \\
\hline Assist device procedures & $656^{\mathrm{a}}$ & $2,375^{\mathrm{a}}$ & 3,031 & $+15.2 \%$ \\
\hline Extracardiac surgery & $363^{\mathrm{a}}$ & 48,796 & 49,159 & $-9.5 \%$ \\
\hline $\begin{array}{l}\text { Pacemaker and ICD } \\
\text { procedures }\end{array}$ & $32^{\mathrm{a}}$ & 20,212 & 20,244 & $-5.0 \%$ \\
\hline Total & 63,720 & $\mathbf{9 8 , 0 9 7}$ & $\mathbf{1 6 1 , 8 1 7}$ & $-7.9 \%$ \\
\hline
\end{tabular}

${ }^{a}$ Sum: $n=92,809$ (heart surgery procedures).

Table 6 Gender distribution

\begin{tabular}{|c|c|c|c|c|}
\hline \multirow[t]{2}{*}{ Distribution } & \multicolumn{2}{|l|}{ Female } & \multicolumn{2}{|l|}{ Male } \\
\hline & $n$ & $\%$ & $n$ & $\%$ \\
\hline Heart valve procedures & 15,302 & 43 & 20,167 & 57 \\
\hline Coronary procedures & 7,786 & 20 & 30,198 & 80 \\
\hline CHD procedures & 2,481 & 45 & 3,088 & 55 \\
\hline Surgery of thoracic aorta & 2,642 & 34 & 5,190 & 66 \\
\hline Cardiac surgery, other & 1,457 & 58 & 1,072 & 42 \\
\hline Assist device & 773 & 26 & 2,258 & 74 \\
\hline Pacemaker and ICD & 7,672 & 38 & 12,572 & 62 \\
\hline Extracardiac surgery & 16,274 & 33 & 32,885 & 67 \\
\hline Total & 54,387 & 34 & 107,430 & 66 \\
\hline
\end{tabular}

Table V1 Isolated heart valve procedures

\begin{tabular}{|l|l|l|l|}
\hline Procedure & $\boldsymbol{n}$ & $\dagger$ & $\%$ \\
\hline Single valve & 14,773 & 479 & 3.2 \\
\hline Double valve & 2,836 & 237 & 8.4 \\
\hline Triple valve & 289 & 34 & 11.8 \\
\hline $\begin{array}{l}\text { Transcatheter access } \\
\text { (single valve) }\end{array}$ & 17,443 & 400 & 2.3 \\
\hline $\begin{array}{l}\text { Transcatheter access } \\
\text { (double valve) }\end{array}$ & 28 & 3 & 10.7 \\
\hline Unspecified & 100 & 12 & 12.0 \\
\hline Total & 35,469 & 1,165 & 3.3 \\
\hline
\end{tabular}

Notes: Transcatheter heart valve procedures: 15,701 aortic valve implantation; 161 mitral valve implantation; 1,325 mitral valve repair; 6 tricuspid valve implantation; 250 tricuspidal valve repair; 28 double aortic and mitral valve procedure; no pulmonary valve implantation.
Table 7 Additional data 2020 versus 2019

\begin{tabular}{|l|l|l|l|l|}
\hline Procedures with ECC & \multicolumn{2}{|l|}{2020} & \multicolumn{2}{l|}{2019} \\
\hline Emergency & 10,445 & $11.3 \%$ & 10,861 & $10.8 \%$ \\
\hline Redo & 7,330 & $7.9 \%$ & 8,481 & $8.4 \%$ \\
\hline
\end{tabular}

Table V2 Single heart valve procedures

\begin{tabular}{|l|l|l|l|}
\hline Access path & $n$ & $\dagger$ & $\%$ \\
\hline Aortic valve & & & \\
\hline Sternotomy & 5,180 & 189 & 3.6 \\
\hline Partial sternotomy & 3,006 & 31 & 1.0 \\
\hline Transvascular & 14,345 & 296 & 2.1 \\
\hline Transapical & 1,356 & 73 & 5.4 \\
\hline Mitral valve & & & \\
\hline Sternotomy & 2,708 & 174 & 6.4 \\
\hline Minimal invasive & 3,342 & 45 & 1.3 \\
\hline Transcatheter & 1,486 & 26 & 1.7 \\
\hline Tricuspidal valve & & & \\
\hline Sternotomy & 340 & 35 & 10.3 \\
\hline Minimal invasive & 138 & 5 & 3.6 \\
\hline Transcatheter & 256 & 5 & 2.0 \\
\hline Pulmonary valve & & 0 & \\
\hline Sternotomy & 57 & 0 & 0.0 \\
\hline Minimal invasive & 0 & 0 & - \\
\hline Transcatheter & 0 & & -7 \\
\hline Total & 32,214 & & \\
\hline & & 0 & \\
\hline
\end{tabular}

Apical aortic conduits procedures $(n=2)$ are not included.

Table V3 Isolated aortic/mitral valve operations

\begin{tabular}{|l|l|l|l|l|l|l|}
\hline $\begin{array}{l}\text { Prosthesis/native } \\
\text { heart valve }\end{array}$ & \multicolumn{4}{|l|}{ Aortic } & \multicolumn{3}{l|}{ Mitral } \\
\cline { 2 - 7 } & $n$ & $\dagger$ & $\%$ & $n$ & $\dagger$ & $\%$ \\
\hline Xenograft & 7.194 & 205 & 2.8 & 1.769 & 156 & 8.8 \\
\hline $\begin{array}{l}\text { Mechanical } \\
\text { prosthesis }\end{array}$ & 830 & 10 & 1.2 & 398 & 17 & 4.3 \\
\hline Repair & 137 & 2 & 1.5 & 3,878 & 45 & 1.2 \\
\hline Homograft & 25 & 3 & 12.0 & 5 & 1 & 20.0 \\
\hline Total & 8,186 & 220 & 2.7 & 6,050 & 219 & 3.6 \\
\hline
\end{tabular}

Note: Transcatheter procedures and apical aortic conduits procedures $(n=2)$ excluded.

Table V4 Isolated/combined mitral valve procedures-implantation/replacement versus repair

\begin{tabular}{|c|c|c|c|c|c|c|c|c|c|}
\hline \multirow[t]{2}{*}{ Mitral valve procedures } & \multicolumn{3}{|l|}{ Repair } & \multicolumn{3}{|c|}{ Implantation/replacement } & \multicolumn{3}{|l|}{ Total } \\
\hline & $n$ & $\dagger$ & $\%$ & $n$ & $\dagger$ & $\%$ & $n$ & $\dagger$ & $\%$ \\
\hline Isolated & 3,878 & 45 & 1.2 & 2,172 & 174 & 8.0 & 6,050 & 219 & 3.6 \\
\hline+ CABG & 1,115 & 71 & 6.4 & 815 & 131 & 16.1 & 1,930 & 202 & 10.5 \\
\hline+ Tricuspid valve repair $^{\mathrm{a}}$ & 825 & 25 & 3.0 & 534 & 57 & 10.7 & 1,359 & 82 & 6.0 \\
\hline+ Aortic valve & 447 & 23 & 5.1 & 760 & 104 & 13.7 & 1,207 & 127 & 10.5 \\
\hline+ CABG + aortic valve replacement & 207 & 20 & 9.7 & 274 & 53 & 19.3 & 481 & 73 & 15.2 \\
\hline Total & 6,472 & 184 & 2.8 & 4,555 & 519 & 11.4 & 11,027 & 703 & 6.4 \\
\hline
\end{tabular}

${ }^{\mathrm{a}}$ Forty-seven procedures (not specified mitral valve + tricuspid valve surgery) excluded, Mortality: 15\% (7/47). 
Table V5 Multiple heart valve procedures

\begin{tabular}{|l|l|l|l|}
\hline Combination & $n$ & $\dagger$ & \% \\
\hline Mitral + tricuspid & 1,406 & 89 & 127 \\
\hline Aortic + mitral & 1,207 & 34 & 10.5 \\
\hline Aortic + mitral + tricuspid & 287 & 11.8 \\
\hline Aortic + tricuspid & 155 & 18 & 1 \\
\hline Aortic + pulmonary & 58 & 11.6 \\
\hline Tricuspid + pulmonary & 10 & 2 & 1.7 \\
\hline Aortic + mitral + pulmonary & 2 & 0 & 20.0 \\
\hline Total & 3,125 & 271 \\
\hline
\end{tabular}

Notes: Transcatheter procedures are excluded.

ancluding Ross procedures.

Table V6 Transcatheter heart valve procedures

\begin{tabular}{|c|c|c|c|c|c|c|c|}
\hline & \multicolumn{2}{|c|}{ Without ECC } & \multicolumn{2}{|c|}{ With ECC } & \multicolumn{3}{|l|}{ Total } \\
\hline & $n$ & $\dagger$ & $n$ & $\dagger$ & $n$ & $\dagger$ & $\%$ \\
\hline Aortic valve implantation & 15,621 & 347 & 80 & 22 & 15,701 & 369 & 2.4 \\
\hline Transvascular & 14,275 & 277 & 70 & 19 & 14,345 & 296 & 2.1 \\
\hline Transapical & 1,346 & 70 & 10 & 3 & 1,356 & 73 & 5.4 \\
\hline Mitral valve & 1,428 & 24 & 58 & 2 & 1,486 & 26 & 1.7 \\
\hline Implantation & 149 & 10 & 12 & 2 & 161 & 12 & 7.5 \\
\hline Tricuspid valve repair & 256 & 5 & 0 & 0 & 256 & 5 & 2.0 \\
\hline Repair & 250 & 4 & 0 & 0 & 250 & 4 & 1.6 \\
\hline Implantation & 6 & 1 & 0 & 0 & 6 & 1 & 16.7 \\
\hline Aortic + mitral valve implantation & 27 & 3 & 1 & 0 & 28 & 3 & 10.7 \\
\hline Aortic valve implantation $^{\mathrm{a}}+\mathrm{CABG}$ & 21 & 1 & 16 & 8 & 37 & 9 & 24.3 \\
\hline Aortic + mitral valve + CABG & 0 & 0 & 0 & 0 & 0 & 0 & - \\
\hline Total & 17,354 & 380 & 159 & 33 & 17,513 & 413 & 2.4 \\
\hline
\end{tabular}

Notes: Pulmonary valve implantation for CHD excluded; $9 \%$ of TAVI by transapical access and less than 1\% of TAVI under ECC conditions.

${ }^{\mathrm{a}}$ Femoral, subclavian, or transaortic access.

${ }^{\text {b}}$ Transvascular and transapical access.

Table C1 Isolated CABG and combined procedures with ECC

\begin{tabular}{|c|c|c|c|}
\hline & $n$ & $\dagger$ & $\%$ \\
\hline Isolated CABG & 29,444 & 830 & 2.8 \\
\hline + Aortic valve replacement & 4,436 & 198 & 4.5 \\
\hline+ Other & 1,582 & 96 & 6.1 \\
\hline + Mitral valve repair & 1,115 & 71 & 6.4 \\
\hline + Mitral valve replacement & 815 & 131 & 16.1 \\
\hline+ Aortic valve replacement + mitral valve repair & 207 & 20 & 9.7 \\
\hline+ Aortic + mitral valve replacement & 274 & 53 & 19.3 \\
\hline + Aneurysm resection & 69 & 3 & 4.3 \\
\hline + Transcatheter aortic valve implantation & 37 & 9 & 24.3 \\
\hline + Transcatheter mitral valve procedure & 5 & 1 & 20.0 \\
\hline Total & 37,984 & 1,412 & 3.7 \\
\hline
\end{tabular}


Table C2 Isolated CABG on-/off-pump surgery

\begin{tabular}{|c|c|c|c|c|c|c|c|c|c|}
\hline \multirow[t]{2}{*}{ Grafts } & \multicolumn{3}{|c|}{ On-pump } & \multicolumn{3}{|c|}{ Off-pump } & \multicolumn{3}{|l|}{ Total } \\
\hline & $n$ & $\dagger$ & $\%$ & $n$ & $\dagger$ & $\%$ & $n$ & $\dagger$ & $\%$ \\
\hline Single & 748 & 42 & 5.6 & 1,225 & 24 & 2.0 & 1,973 & 66 & 3.3 \\
\hline Double & 4,491 & 166 & 3.7 & 1,682 & 39 & 2.3 & 6,173 & 205 & 3.3 \\
\hline Triple & 9,850 & 280 & 2.8 & 2,443 & 43 & 1.8 & 12,293 & 323 & 2.6 \\
\hline Quadruple & 5,740 & 146 & 2.5 & 869 & 18 & 2.1 & 6,609 & 164 & 2.5 \\
\hline Quintuple + more & 2,175 & 69 & 3.2 & 221 & 3 & 1.4 & 2,396 & 72 & 3.0 \\
\hline Total & 23,004 & 703 & 3.1 & 6,440 & 127 & 2.0 & 29,444 & 830 & 2.8 \\
\hline
\end{tabular}

Table Con1 Congenital heart surgery with/without ECC

\begin{tabular}{|c|c|c|c|c|c|c|}
\hline \multirow[t]{2}{*}{ Age $(y)$} & \multicolumn{2}{|c|}{$n$} & \multicolumn{2}{|c|}{$\dagger$} & \multicolumn{2}{|c|}{$\%$} \\
\hline & With ECC & Without ECC & With ECC & Without ECC & With ECC & Without ECC \\
\hline$<1$ & 2,084 & 660 & 78 & 17 & 3.7 & 2.6 \\
\hline $1-17$ & 1,832 & 167 & 21 & 1 & 1.1 & 0.6 \\
\hline$\geq 18$ & 866 & 28 & 28 & 0 & 3.2 & 0.0 \\
\hline Total & 4,782 & 855 & 127 & 18 & 2.7 & 2.1 \\
\hline
\end{tabular}

Table Con2 Procedures for congenital heart disease with and without ECC

\begin{tabular}{|c|c|c|c|c|c|c|c|c|c|}
\hline \multirow[t]{2}{*}{ Lesion/Procedure } & \multicolumn{3}{|c|}{ Age $<1$ year } & \multicolumn{3}{|c|}{ Age 1 to 17 years } & \multicolumn{3}{|c|}{ Age $\geq 18$ years } \\
\hline & $n$ & $\dagger$ & $\%$ & $n$ & $\dagger$ & $\%$ & $n$ & $\dagger$ & $\%$ \\
\hline ASD & 34 & 0 & 0.0 & 245 & 0 & 0.0 & 208 & 7 & 3.4 \\
\hline Complete AV-canal & 217 & 5 & 2.3 & 93 & 3 & 3.2 & 6 & 0 & 0.0 \\
\hline VSD & 335 & 2 & 0.6 & 91 & 1 & 1.1 & 17 & 2 & 11.8 \\
\hline Fallot's tetralogy & 182 & 1 & 0.5 & 41 & 0 & 0.0 & 1 & 0 & 0.0 \\
\hline DORV & 55 & 2 & 3.6 & 21 & 1 & 4.8 & 1 & 0 & 0.0 \\
\hline TGA & 144 & 3 & 2.1 & 9 & 0 & 0.0 & 0 & - & - \\
\hline $\mathrm{TGA}+\mathrm{VSD}$ & 61 & 2 & 3.3 & 5 & 0 & 0.0 & 0 & - & - \\
\hline Truncus arteriosus & 31 & 2 & 6.5 & 6 & 0 & 0.0 & 0 & - & - \\
\hline Fontan circulation & 0 & - & - & 250 & 0 & 0.0 & 4 & 0 & 0.0 \\
\hline Norwood & 142 & 23 & 16.2 & 3 & 0 & 0.0 & 0 & - & - \\
\hline Pulmonary valve & 60 & 1 & 1.7 & 217 & 3 & 1.4 & 57 & 1 & 1.8 \\
\hline Transcatheter pulmonary valve implantation & 0 & - & - & 0 & - & - & 10 & 0 & 0.0 \\
\hline Aortic valve & 59 & 1 & 1.7 & 214 & 3 & 1.4 & 333 & 7 & 2.1 \\
\hline Ross procedure & 8 & 2 & 25.0 & 27 & 0 & 0.0 & 19 & 0 & 0.0 \\
\hline Mitral valve & 44 & 1 & 2.3 & 123 & 0 & 0.0 & 84 & 4 & 4.8 \\
\hline Tricuspid valve & 141 & 1 & 0.7 & 83 & 2 & 2.4 & 49 & 5 & 10.2 \\
\hline PDA & 133 & 2 & 1.5 & 20 & 0 & 0.0 & 1 & 0 & 0.0 \\
\hline Coarctation & 239 & 4 & 1.7 & 33 & 0 & 0.0 & 3 & 0 & 0.0 \\
\hline Others & 857 & 43 & 5.0 & 483 & 7 & 1.4 & 101 & 2 & 2.0 \\
\hline HTx & 1 & 0 & 0.0 & 24 & 2 & 8.3 & 0 & - & - \\
\hline HLTx & 0 & - & - & 0 & - & - & 0 & - & - \\
\hline LTx & 1 & 0 & 0.0 & 11 & 0 & 0.0 & 0 & - & - \\
\hline Total & 2,744 & 95 & 3.5 & 1,999 & 22 & 1.1 & 894 & 28 & 3.1 \\
\hline
\end{tabular}


302 German Heart Surgery Report 2020 Beckmann et al.

Table Mis1 Ross procedures (autologous AV and PVR)

\begin{tabular}{|c|c|c|c|c|c|c|c|c|c|c|}
\hline Age (y) & 2011 & 2012 & 2013 & 2014 & 2015 & 2016 & 2017 & 2018 & 2019 & 2020 \\
\hline$<18$ & 40 & 36 & 33 & 37 & 28 & 38 & 38 & 29 & 32 & 35 \\
\hline$\geq 18$ & 134 & 117 & 107 & 90 & 64 & 72 & 52 & 61 & 104 & 70 \\
\hline Total & 174 & 153 & 140 & 127 & 92 & 110 & 90 & 90 & 136 & 105 \\
\hline
\end{tabular}

Table Mis2 Heart and lung transplantation

\begin{tabular}{|l|c|c|c|c|c|}
\hline \multirow{2}{*}{ Transplant } & \multicolumn{3}{|c|}{ With ECC } & \multicolumn{2}{c|}{ Without ECC } \\
\cline { 2 - 7 } & $\boldsymbol{n}$ & $\dagger$ & $\%$ & $\boldsymbol{n}$ & $\dagger$ \\
\hline HTx & 340 & 30 & 8.8 & & \\
\hline HLTx & 1 & 0 & 0.0 & & \\
\hline LTx & 40 & 3 & 7.5 & 251 & 18 \\
\hline
\end{tabular}

Notes: All pediatric transplantations (demonstrated in Table Con2) are included in this table.

Eurotransplant (ET) report 2020: 327 HTx, 10 HTx + kidneyTx, 1 HTx + liverTx, 1 HLTx, 315 DLTx, 25 SLTx, 1 LTx + kidneyTx and 2 LTx + liverTx.

Table Mis3 Aortic surgery

\begin{tabular}{|c|c|c|c|c|c|c|}
\hline \multirow[t]{2}{*}{ Replacement $^{\mathrm{a}}$} & \multicolumn{3}{|c|}{ With ECC } & \multicolumn{3}{|c|}{ Without ECC } \\
\hline & $n$ & $\dagger$ & $\%$ & $n$ & $\dagger$ & $\%$ \\
\hline Supracoronary replacement of ascending aorta & 1,166 & 106 & 9.1 & & & \\
\hline Supracoronary ascending + aortic valve replacement & 1,205 & 50 & 4.1 & & & \\
\hline \multicolumn{7}{|l|}{ Infracoronary replacement of ascending aorta } \\
\hline Mechanical aortic valve conduits & 327 & 20 & 6.1 & & & \\
\hline Biological aortic conduits & 1,046 & 102 & 9.8 & & & \\
\hline David procedure & 517 & 9 & 1.7 & & & \\
\hline Yacoub procedure & 101 & 3 & 3.0 & & & \\
\hline Other & 274 & 28 & 10.2 & & & \\
\hline Aortic arch replacement ${ }^{b}$ & 2,396 & 345 & 14.4 & & & \\
\hline Replacement of descending aorta & 60 & 6 & 10.0 & 4 & 0 & 0.0 \\
\hline Thoraco-abdominal aortic replacement & 82 & 15 & 18.3 & 18 & 1 & 5.6 \\
\hline Endostent descending aorta & 3 & 1 & 33.3 & 633 & 27 & 4.3 \\
\hline Total & 7,177 & 685 & 9.5 & 655 & 28 & 4.3 \\
\hline
\end{tabular}

Notes: All procedures involving aortic surgery are included in this table, Isolated aortic surgery as well as all possible combined procedures (e.g. additional $(A B G)$ are summarized in this category.

aprocedures for abdominal aortic diseases excluded: 463, abdominal procedures and 21 endovascular abdominal stents.

${ }^{\mathrm{b}}$ All possible combined procedures included; the only common denominator is aortic arch surgery.

Table Mis4 Pacemaker and ICD procedures

\begin{tabular}{|c|c|c|c|c|c|c|c|}
\hline \multirow[t]{2}{*}{ Device/Category } & \multirow[b]{2}{*}{$n$} & \multirow[b]{2}{*}{$\dagger$} & \multirow[b]{2}{*}{$\%$} & \multicolumn{2}{|c|}{ With ECC } & \multicolumn{2}{|c|}{ Without ECC } \\
\hline & & & & $n$ & $\dagger$ & $n$ & $\dagger$ \\
\hline Pacemaker & 12,698 & 85 & 0.7 & 14 & 2 & 12,684 & 83 \\
\hline Implantation & 8,510 & 58 & 0.7 & 2 & 0 & 8,508 & 58 \\
\hline Battery exchange & 1,662 & 2 & 0.1 & 0 & 0 & 1,662 & 2 \\
\hline Revision procedures & 2,526 & 25 & 1.0 & 12 & 2 & 2,514 & 23 \\
\hline ICD & 6,489 & 58 & 0.9 & 16 & 4 & 6,473 & 54 \\
\hline Implantation & 2,741 & 7 & 0.3 & 0 & 0 & 2,741 & 7 \\
\hline Battery exchange & 1,427 & 1 & 0.1 & 0 & 0 & 1,427 & 1 \\
\hline Revision procedures & 2,321 & 50 & 2.2 & 16 & 4 & 2,305 & 46 \\
\hline Miscellaneous & 1,057 & 4 & 0.4 & 2 & 0 & 1,055 & 4 \\
\hline Total & 20,244 & 147 & 0.7 & 32 & 6 & 20,212 & 141 \\
\hline
\end{tabular}


Table Mis5 Surgical procedures for tachyarrhythmia

\begin{tabular}{|c|c|c|c|}
\hline \multirow[t]{2}{*}{ Energy source } & Endocardiac & Epicardiac & \multirow[t]{2}{*}{$\mathrm{n}$} \\
\hline & $n$ & $n$ & \\
\hline Unipolar radio frequency & 116 & 191 & 307 \\
\hline Unipolar cooled radio frequency & 41 & 123 & 164 \\
\hline Bipolar radiofrequency & 164 & 1,626 & 1,790 \\
\hline Cryothermy & 1,424 & 351 & 1,775 \\
\hline Microwave & 1 & 7 & 8 \\
\hline Focused ultrasound & 1 & 93 & 94 \\
\hline Laser & 1 & 0 & 1 \\
\hline Other & 7 & 4 & 11 \\
\hline Total & 1,755 & 2,395 & 4,150 \\
\hline
\end{tabular}

Note: 202 procedures are unspecified with regard to endocardiac/epicardiac ablation.

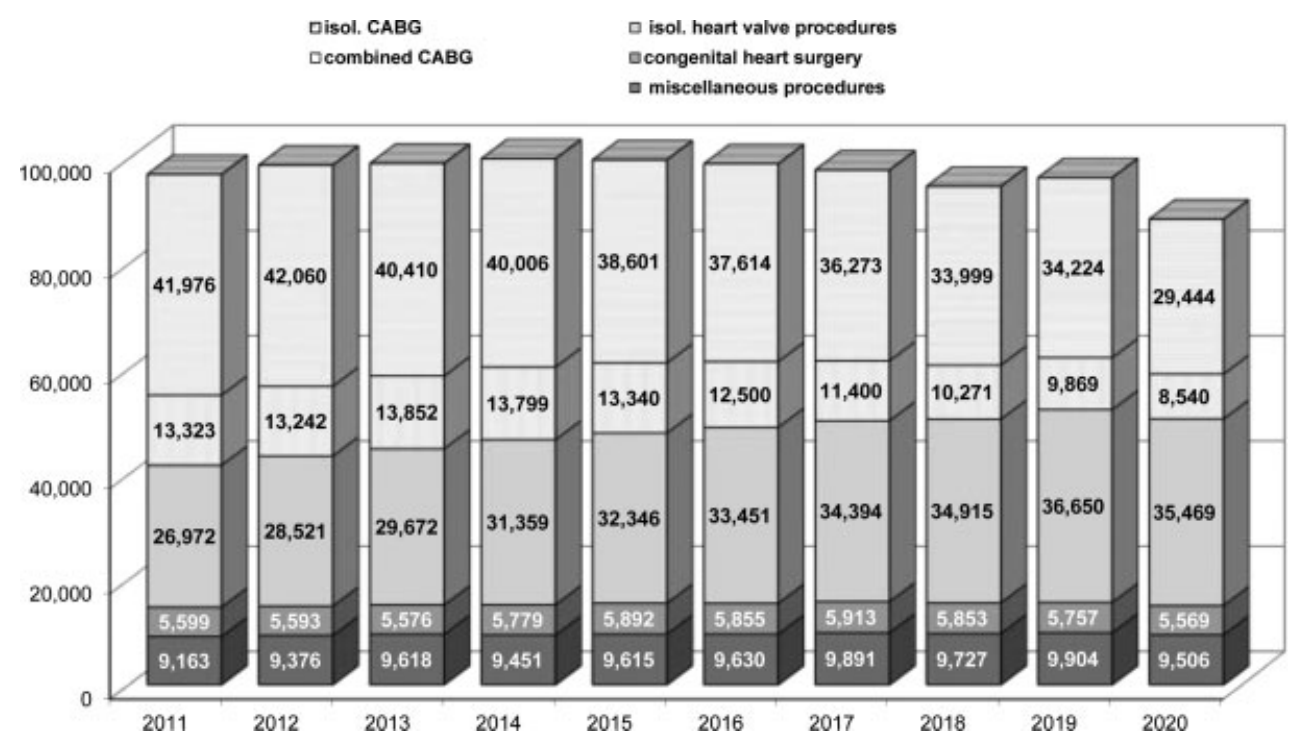

Fig. 1 Selected heart surgical categories (2011-2020). Notes: Congenital heart surgery: Atrial septal defect repairs in adults or in combination with coronary artery bypass grafting (CABG) or heart valve procedures are summarized in the CABG or heart valve procedure groups; miscellaneous procedures: all other types of procedures with extracorporeal circulation.

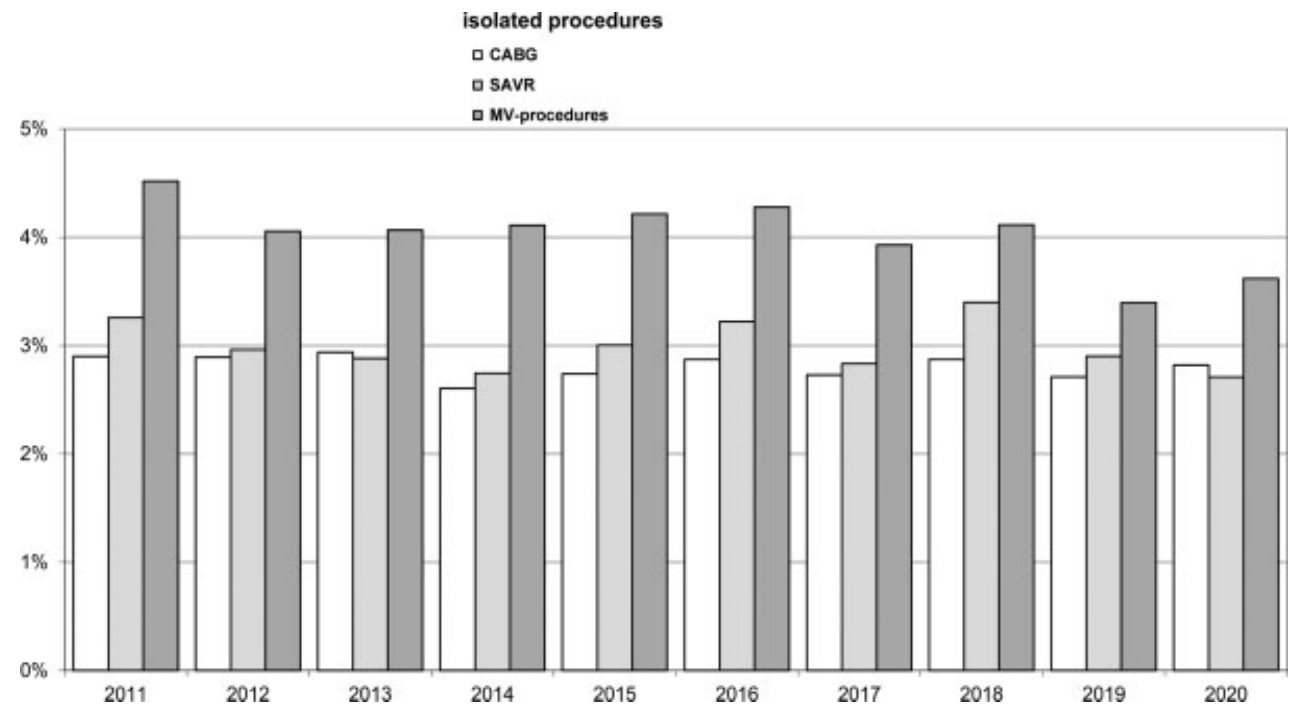

Fig. 2 Unadjusted mortality for selected procedures (2011-2020). 


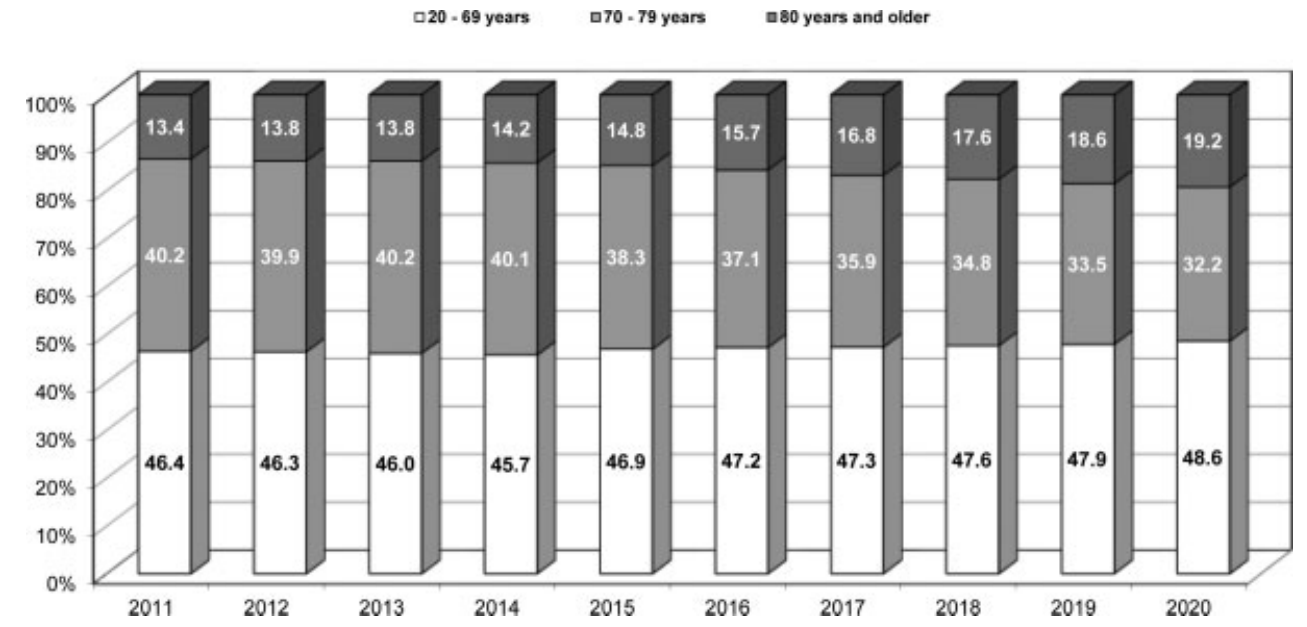

Fig. 3 Age distribution of cardiac procedures (2011-2020). Notes: Patients $<20$ years and CIED procedures excluded.

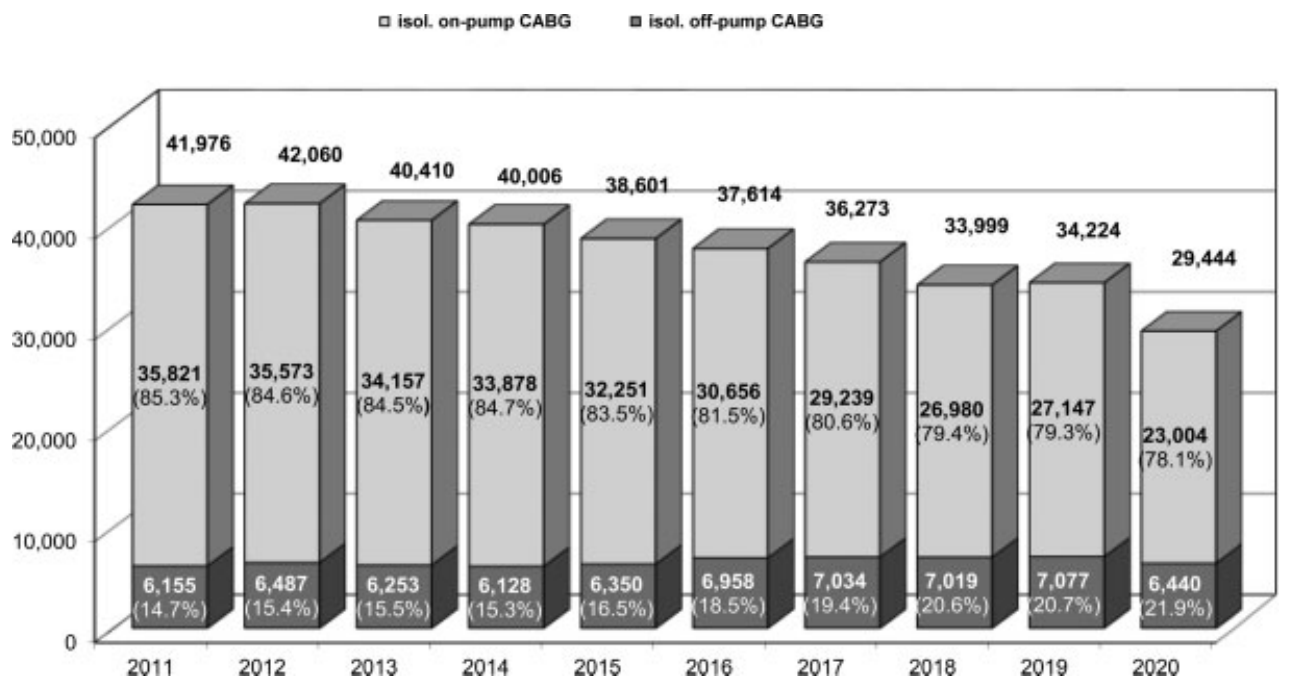

Fig. 4 Isolated coronary artery bypass grafting (CABG) (2011-2020).

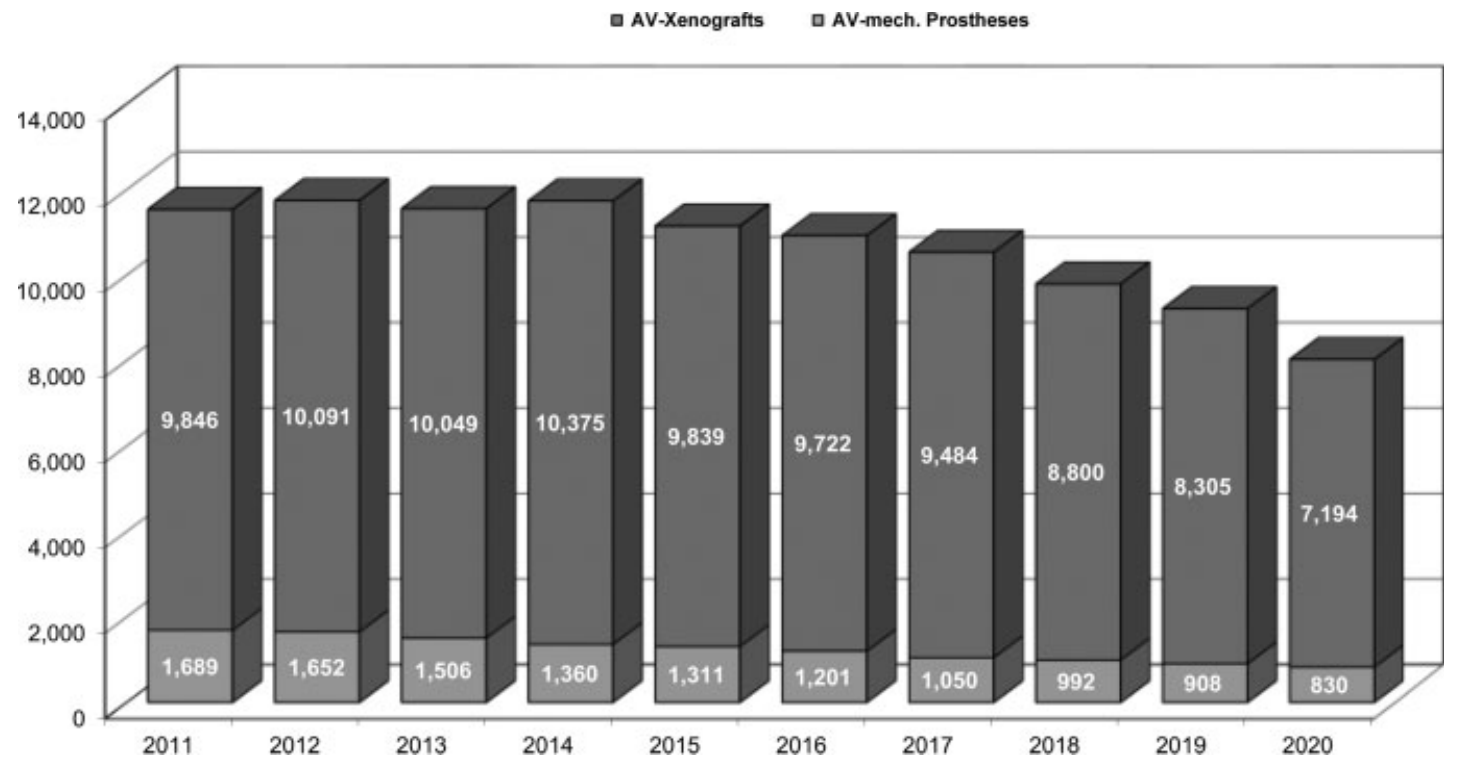

Fig. 5 Isolated aortic valve (AV) replacement (2011-2020). Notes: Ross procedures, homograft implantations, and transcatheter heart valve interventions excluded. 
DTAVI aConventional

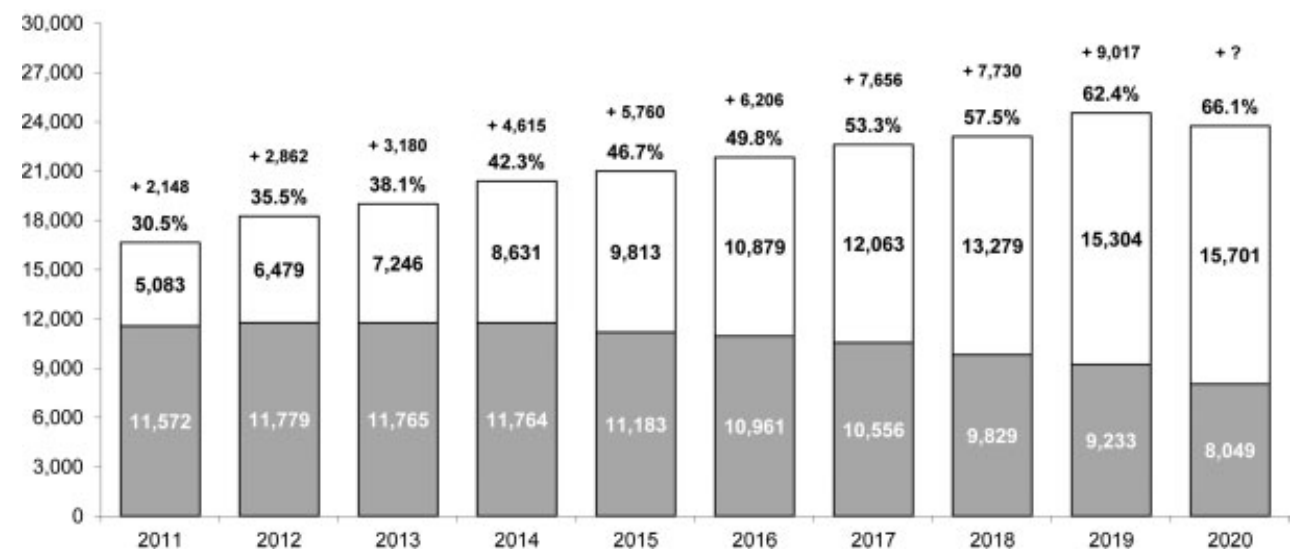

Fig. 6 Isolated aortic valve replacement and transcatheter aortic valve implantation (TAVI). +Additional TAVI procedures calculated from the German legal quality assurance program, §§ 135a/ 136/ 137 SGB V.

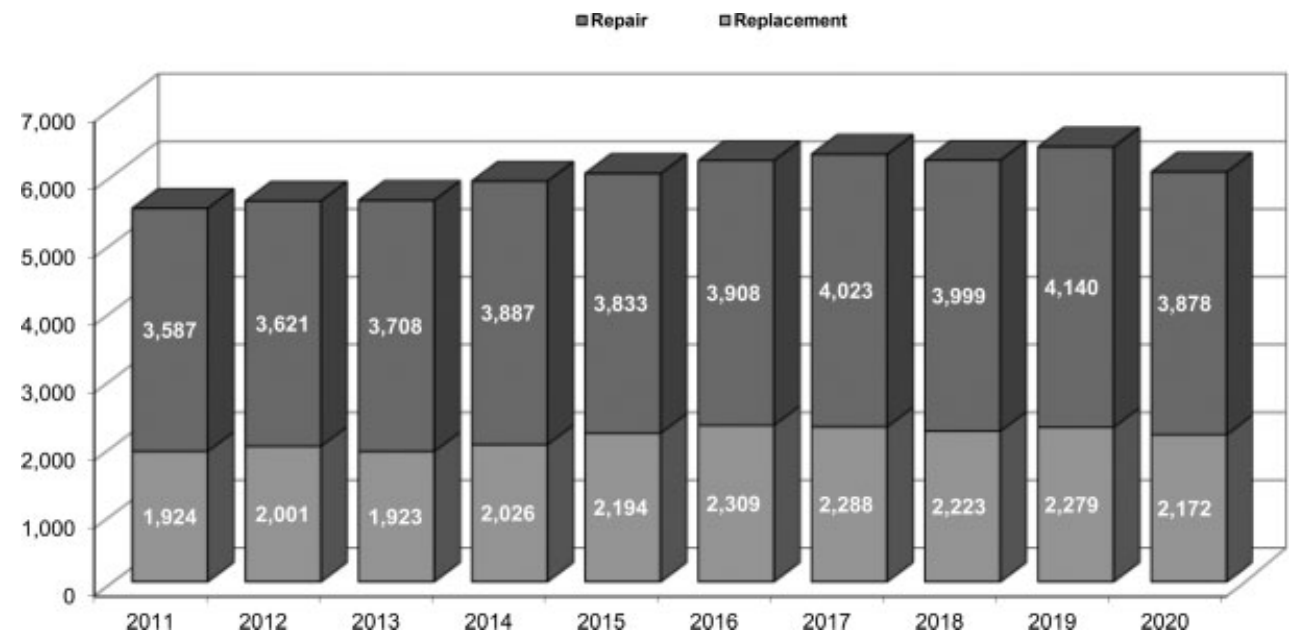

Fig. 7 Isolated mitral valve surgery (2011-2020).

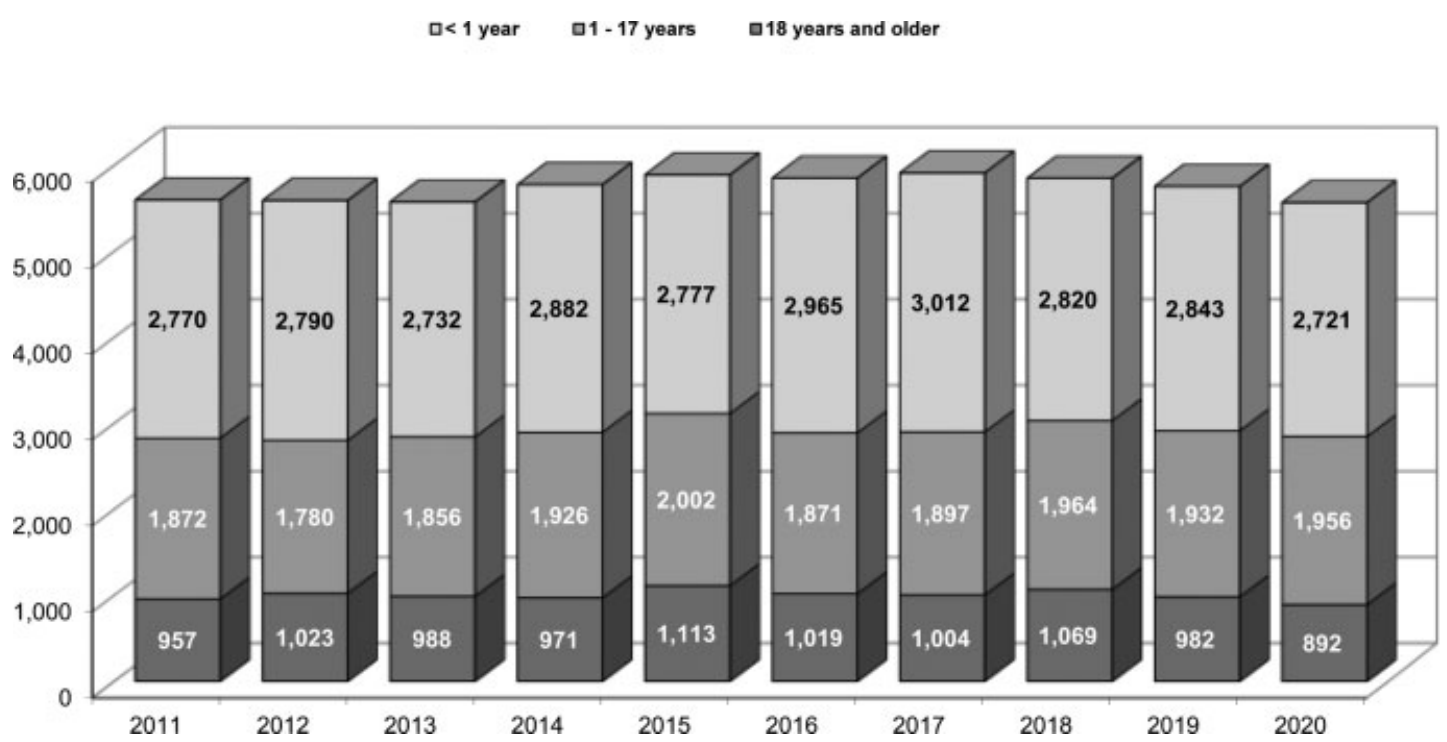

Fig. 8 Age distribution for congenital heart disease (CHD) (2011-2020). Notes: Bias possible due to the fact that not all relevant procedures can be allocated exactly to CHD-category in patients $>18$ years (e.g., aortic valve disease). 


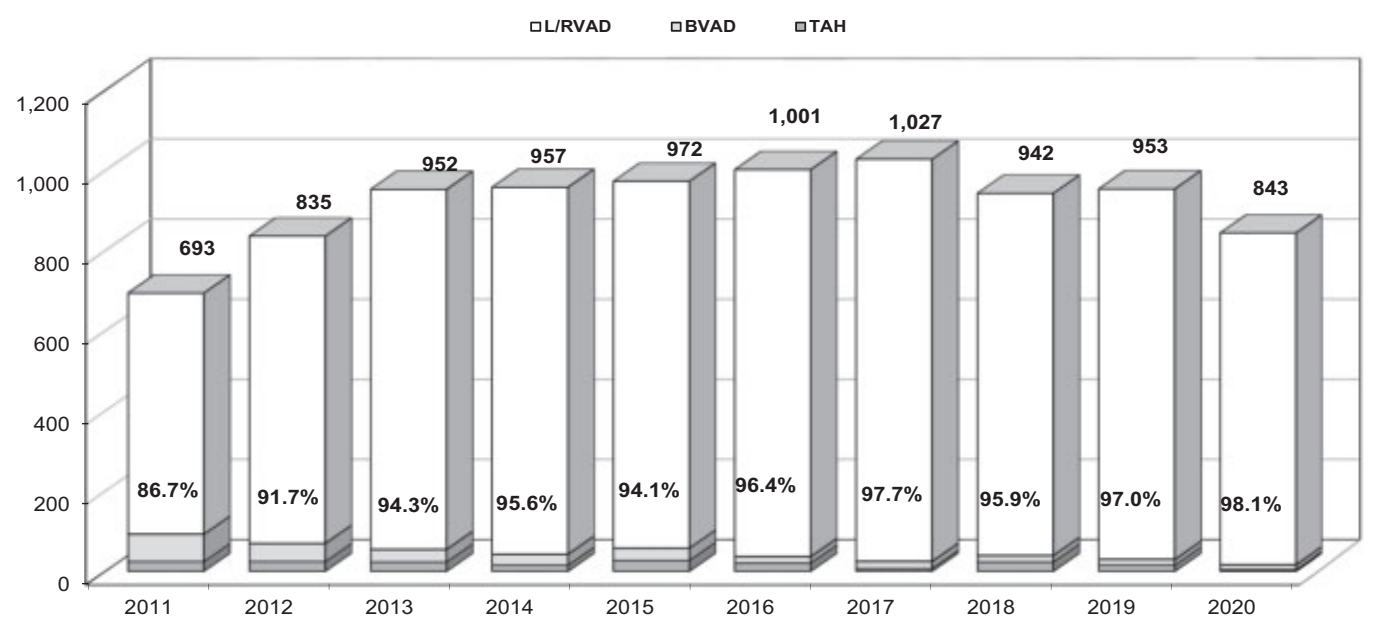

Fig. 9 Mechanical circulatory support devices (2011-2020).

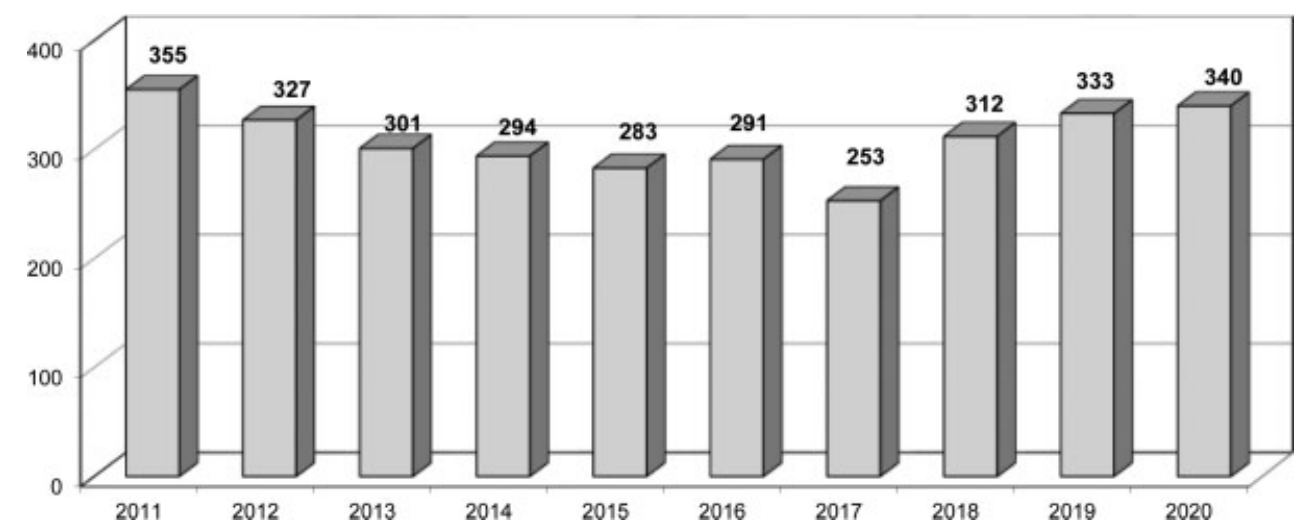

Fig. 10 Heart transplantation (2011-2020).

\section{References}

1 Rodewald G, Polonius MJ. Cardiac surgery in the Federal Republic of Germany during 1978 and 1979. Thorac Cardiovasc Surg 1980; 28(06):373-377

2 Rodewald G, Kalmar P. Cardiac surgery in the Federal Republic of Germany during 1984. Thorac Cardiovasc Surg 1985;33(06): 397-399

3 Kalmar P, Irrgang E. Cardiac surgery in the Federal Republic of Germany during 1988. Thorac Cardiovasc Surg 1989;37(03): 193-195

4 Kalmar P, Irrgang E. Cardiac surgery in the Federal Republic of Germany during 1989. A report by the German Society for Thoracic and Cardiovascular Surgery. Thorac Cardiovasc Surg 1990;38(03):198-200

5 Gummert JF, Funkat A, Krian A. Cardiac surgery in Germany during 2004: a report on behalf of the German Society for Thoracic and Cardiovascular Surgery. Thorac Cardiovasc Surg 2005;53(06):391-399

6 Funkat AK, Beckmann A, Lewandowski J, et al. Cardiac surgery in Germany during 2011: a report on behalf of the German Society for Thoracic and Cardiovascular Surgery. Thorac Cardiovasc Surg 2012;60(06):371-382

7 Beckmann A, Meyer R, Lewandowski J, Markewitz A, Harringer W. German Heart Surgery Report 2018: the annual updated Registry of the German Society for Thoracic and Cardiovascular Surgery. Thorac Cardiovasc Surg 2019;67 (05):331-344
8 Baumgartner H, Falk V, Bax JJ, et al; ESC Scientific Document Group. 2017 ESC/EACTS guidelines for the management of valvular heart disease. Eur Heart J 2017;38(36):2739-2791

9 Nishimura RA, Otto CM, Bonow RO, et al. 2017 AHA/ACC Focused Update of the 2014 AHA/ACC guideline for the management of patients with valvular heart disease: a report of the American College of Cardiology/American Heart Association Task Force on Clinical Practice Guidelines. Circulation 2017;135(25):e1159-e1195

10 Nishimura RA, O'Gara PT, Bavaria JE, et al. 2019 AATS/ACC/ASE/SCAI/STS Expert Consensus Systems of Care Document: a proposal to optimize care for patients with valvular heart disease: a joint report of the American Association for Thoracic Surgery, American College of Cardiology, American Society of Echocardiography, Society for Cardiovascular Angiography and Interventions, and The Society of Thoracic Surgeons. Ann Thorac Surg 2019;107(06):1884-1910

11 Otto CM, Nishimura RA, Bonow RO, et al. 2020 ACC/AHA guideline for the management of patients with valvular heart disease: a report of the American College of Cardiology/American Heart Association Joint Committee on Clinical Practice Guidelines. Circulation 2021;143(05):e72-e227

12 Richtlinie zu minimalinvasiven Herzklappeninterventionen; Richtlinie über Maßnahmen zur Qualitätssicherung bei der Durchführung von minimalinvasiven Herzklappeninterventionen gemäß $§ 136$. Absatz 1 Satz 1 Nummer 2 für nach $\S 108$ SGB V zugelassene Krankenhäuser MHI-RL; Gemeinsamer Bundesausschuss (G-BA): https://www.g-ba.de/richtlinien/84/ 
13 Beckmann A, Hamm C, Figulla HR, et al; GARY Executive Board. The German Aortic Valve Registry (GARY): a nationwide registry for patients undergoing invasive therapy for severe aortic valve stenosis. Thorac Cardiovasc Surg 2012;60(05):319-325

14 Ensminger S, Fujita B, Bauer T, et al; GARY Executive Board. Rapid deployment versus conventional bioprosthetic valve replacement for aortic stenosis. J Am Coll Cardiol 2018;71(13):1417-1428

15 Fujita B, Ensminger S, Bauer T, et al; GARY Executive Board. Trends in practice and outcomes from 2011 to 2015 for surgical aortic valve replacement: an update from the German Aortic Valve Registry on 42776 patients. Eur J Cardiothorac Surg 2018;53 (03):552-559

16 Husser O, Fujita B, Hengstenberg C, et al; GARY Executive Board. Conscious sedation versus general anesthesia in transcatheter aortic valve replacement: the German Aortic Valve Registry. JACC Cardiovasc Interv 2018;11(06):567-578

17 Werner N, Zahn R, Beckmann A, et al. Patients at intermediate surgical risk undergoing interventional or surgical aortic valve implantation for severe aortic stenosis: one year results from the German Aortic Valve Registry. Circulation 2018;138:2611-2623

18 Bekeredjian R, Szabo G, Balaban Ü, et al. Patients at low surgical risk as defined by the Society of Thoracic Surgeons Score undergoing isolated interventional or surgical aortic valve implantation: in-hospital data and 1-year results from the German Aortic Valve Registry (GARY). Eur Heart J 2019;40(17):1323-1330

19 Fujita B, Schmidt T, Bleiziffer S, et al; GARY Executive Board. Impact of new pacemaker implantation following surgical and transcatheter aortic valve replacement on 1-year outcome. Eur J Cardiothorac Surg 2020;57(01):151-159

20 Blumenstein J, Möllmann H, Bleiziffer S, et al. Transcatheter aortic valve implantation in nonagenarians: insights from the German Aortic Valve Registry (GARY). Clin Res Cardiol 2020;109(09): 1099-1106
21 Voigtländer L, Twerenbold R, Schäfer U, et al; GARY Executive Board. Prognostic Impact of Underweight (Body Mass Index $<20 \mathrm{~kg} / \mathrm{m}^{2}$ ) in patients with severe aortic valve stenosis undergoing transcatheter aortic valve implantation or surgical aortic valve replacement (from the German Aortic Valve Registry [GARY]). Am J Cardiol 2020;129:79-86

22 Abdel-Wahab M, Fujita B, Frerker C, et al; GARY Executive Board. Transcatheter versus rapid-deployment aortic valve replacement: a propensity-matched analysis from the German Aortic Valve Registry. JACC Cardiovasc Interv 2020;13(22): 2642-2654

23 Färber G, Bleiziffer S, Doenst T, et al; GARY Executive Board. Transcatheter or surgical aortic valve implantation in chronic dialysis patients: a German Aortic Valve Registry analysis. Clin Res Cardiol 2021;110(03):357-367

24 Gammie JS, Zhao Y, Peterson ED, O’Brien SM, Rankin JS, Griffith BPJ. J. Maxwell Chamberlain Memorial Paper for adult cardiac surgery. Less-invasive mitral valve operations: trends and outcomes from the Society of Thoracic Surgeons Adult Cardiac Surgery Database. Ann Thorac Surg 2010;90(05):1401-1408, 1410.e1, discussion 1408-1410

25 Herbert MA, Prince SL, Williams JL, Magee MJ, Mack MJ. Are unaudited records from an outcomes registry database accurate? Ann Thorac Surg 2004;77(06):1960-1964, discussion 1964-1965

26 Neumann FJ, Sousa-Uva M, Ahlsson A, et al; ESC Scientific Document Group. 2018 ESC/EACTS Guidelines on myocardial revascularization. Eur Heart J 2019;40(02):87-165

27 Bundesärztekammer (BÄK) Kassenärztliche Bundesvereinigung (KBV), Arbeitsgemeinschaft der Wissenschaftlichen Medizinischen Fachgesellschaften (AWMF)Nationale VersorgungsLeitlinie Chronische KHK. https://www.leitlinien.de/nvl/khk [cited: 2020-04-11]. 